\title{
Risks, costs, and compliance limit colorectal adenoma surveillance: lessons from a randomised trial
}

J N Lund, J H Scholefield, M J Grainge, S J Smith, C Mangham, N C Armitage, M H Robinson, R F A Logan

\begin{abstract}
Background and aims-In the USA and many other countries, endoscopic surveillance of colorectal adenoma patients is now widely practised. However, the optimal frequency and mode of such surveillance are not yet established. The aim of this trial was to compare surveillance at one, two, or five year intervals using either flexible sigmoidoscopy or colonoscopy.

Methods-Analysis of a randomised trial of flexible sigmoidoscopy and colonoscopy over one, two, or five years after stratification for "high" or "low" risk of recurrent adenomas. The trial started in 1984.

Results-A total of 776 patients were stratified into "high" $(n=307)$ and "low" $(n=469)$ recurrence risk groups and randomised to flexible sigmoidoscopy or colonoscopy at varying intervals. Only 81 recurrent adenomas (30/81 were $>1 \mathrm{~cm}$ in diameter) were detected in the 2307 person years of follow up within the surveillance study. Adenoma recurrence was significantly higher in the high risk group (relative rate $1.82 ; 95 \%$ confidence interval 1.2-2.9) but recurrence rates per 1000 person years were low and not significantly different in those surveyed by colonoscopy or flexible sigmoidoscopy. Loss to follow up was greatest in those having an annual examination compared with two or five yearly surveillance examinations. Despite surveillance, invasive cancer developed in four patients compared with an expected value of 9.12 for the general population in England $(p=0.10)$; of these four patients who developed cancers, only one was detected by surveillance examination.
\end{abstract}

Conclusions-Adenoma recurrence rates were much lower than expected in both high and low risk groups. This suggests that endoscopic surveillance should be targeted at high risk groups. A surveillance interval of five years was as effective as shorter intervals in terms of cancer prevention, and was associated with similar compliance to two yearly examinations.

(Gut 2001;49:91-96)

Keywords: adenoma; polyp; colorectal cancer; surveillance; colonoscopy
The colorectal "adenoma-carcinoma" sequence is generally accepted to account for $80 \%$ or more of colorectal cancer occurrence ${ }^{12}$ and several studies have shown that regular surveillance and removal of colorectal adenomas is associated with a decreased incidence of colorectal cancer. ${ }^{3-8}$ As a consequence, endoscopic surveillance is now widely practised in the UK. However, it is not yet known how this should be done and how frequently. Recommendations have varied from annually up to 10 yearly. To answer these questions, a randomised controlled trial of colorectal adenoma surveillance was started in Nottingham in 1984.

This study was commenced in 1984 to determine whether removal of adenomas led to a reduction in the incidence of colorectal cancer. At this time the recurrence rate for adenomas and rate of progression from adenoma to carcinoma were both thought to be much greater than is currently believed to be the case. Therefore, the trial was established to randomise patients to one of six different surveillance strategies, each of which reflected current practice in the UK at that time. The major role for flexible sigmoidoscopy in 1984 reflected the prevalent practices at the time (that is, a lack of trained colonoscopists and the belief that "marker" polyps in the left colon would predict those patients needing full colonoscopy).

The aims of the trial were to investigate whether regular endoscopic surveillance and polypectomy would decrease the incidence of invasive colorectal cancer in the study population and to determine if identification of low and high risk groups would allow less frequent surveillance in the low risk group. This study also addressed the optimum surveillance interval and whether a flexible sigmoidoscopy was adequate surveillance.

The trial was terminated in January 1995 when it became clear that adenoma recurrence rates were lower than expected and the trial would not have the power to detect anticipated differences between surveillance strategies. We report the outcome of the trial and examine whether surveillance and polypectomy reduced the expected incidence of colorectal cancer in the trial population.

\section{Methods}

PATIENTS

Patients were recruited from those undergoing colonoscopy for the following reasons: (i) colorectal symptoms, including rectal bleeding;
Accepted for publication 17 January 2001 
(ii) possible polyp or other incidental findings on barium enema; or (iii) investigation of positive faecal occult bloods detected in the Nottingham colorectal cancer screening trial or other studies. Those found to have colonic adenomas between June 1984 and January 1995 were considered for recruitment to one of six surveillance strategies involving either colonoscopy two yearly or five yearly or flexible sigmoidoscopy yearly, two yearly, or five yearly (table 1).

At the initial examination the colon was cleared of polyps and if intubation was not to the caecum a barium enema was performed to ensure a clean colon. Six months after the initial examination a further flexible sigmoidoscopy was performed to ensure a clean left colon. Patients were then stratified into groups with a high or low risk of adenoma recurrence, according to findings at the time of presentation. Those patients perceived as at high risk of recurrent adenomas were those with one or more of the following criteria: an adenoma $>2$ $\mathrm{cm}$; adenomas containing areas of severe dysplasia; and more than two adenomas or a strong family history of colorectal cancer (two or more first degree relatives with colorectal cancer). The remaining patients were considered to have a low risk of recurrence. Those with a weak family history (that is, a second degree relative only) were randomised to the low risk groups if polyp features allowed. Patients were randomised to one of the follow up strategies (table 1) within the stratified groups by drawing a number between one and three from a hat. At each randomisation all three numbers were available.

\section{RECORDING OF DATA}

A register of patients in the trial was maintained by a dedicated trial secretary responsible for organising follow up appointments. Follow up appointments were booked on a hospital computerised system and patients were sent appointments by letter at the appropriate interval. Those failing to attend for follow up investigation were sent a further personalised letter outlining the need for follow up and a letter was also sent to their general practitioner asking that the patient be encouraged to attend. Patients attending for flexible sigmoidoscopy had a $150 \mathrm{ml}$ phosphate enema administered 30 minutes before examination; patients undergoing colonoscopy (and those undergoing completion barium enema) had full bowel preparation using sodium picosulphate (Picolax; Nordic, Langley, Berks, UK).
Flexible sigmoidoscopy and colonoscopic examinations were undertaken by a number of individuals over the period of this study. In general, the flexible sigmoidscopy examinations were carried out by registrars and the colonoscopies by consultants and senior registrars. Polyps identified at flexible sigmoidoscopy were biopsied for histopathological examination. Patients with adenomatous polyps identified on flexible sigmoidoscopy were referred for colonoscopy and endoscopic removal. Adenomas identified at colonoscopy were snared and retrieved for histopathological examination. All biopsies and polyps were fixed in formalin and processed in the institution's routine manner. Histopathology reports were collected centrally by the secretary administering the database.

Data were retrieved retrospectively from hospital notes and pathology records and held on a customised database (Fox Pro 2.0). Data analysis was performed using SAS v.6.12 (SAS Institute, Inc., Gary, North Carolina, USA). Patients were actively followed within the surveillance study and passively followed beyond this time by means of the NHS Central Register. Within the surveillance study person years of follow up were calculated up until the first episode of polyp recurrences or last follow up visit and the polyp recurrence rate derived for each randomisation group. For patients in the Nottingham faecal occult blood screening study, total follow up was until March 1998; for patients not in this study total follow up was until the last visit within the surveillance study. Total follow up within five year age bands by sex were also calculated from which the expected number of colorectal cancers was obtained. The total number of observed cancers was compared with the total number of expected cancers using the Poisson distribution, and a two sided $\mathrm{p}$ value calculated.

\section{ESTIMATION OF EXPECTED COLORECTAL CANCER} INCIDENCE

Colorectal cancer incidence rates from the Thames Cancer Registry were used to compute the expected incidence of colorectal cancer occurring in the study population (Thames Cancer Registry: personal communication, V Mak, 1998). Eighty per cent of those randomised in the study were also part of the population recruited to the Nottingham faecal occult blood screening trial in which the records of all subjects have been flagged in the NHS Central Register (Southport, UK) ensuring automatic notification of all cancers and deaths. This allowed cross referencing of cases

Table 1 Demographic and adenoma characteristics at trial entry

\begin{tabular}{|c|c|c|c|c|c|c|c|c|c|}
\hline Group & Strategy & $n$ & $\%$ Male & $\begin{array}{l}\text { Age } \\
\text { (mean) }\end{array}$ & $\begin{array}{l}\% F O B \\
\text { detected }\end{array}$ & No adenomas ${ }^{1}$ & $\begin{array}{l}\% \geqslant 1 \mathrm{~cm} \\
\text { size }\end{array}$ & $\begin{array}{l}\text { \% Severe } \\
\text { dysplasia }{ }^{2}\end{array}$ & $\begin{array}{l}\text { \%Villous/ } \\
\text { tubulovillous }\end{array}$ \\
\hline \multirow[t]{3}{*}{ High risk } & (1) 1 yearly FS & 115 & 58 & 63.0 & 55 & 188 & 67 & 41 & 51 \\
\hline & (2) 2 yearly FS & 104 & 71 & 63.1 & 63 & 178 & 59 & 20 & 47 \\
\hline & (3) 2 yearly colonoscopy & 86 & 72 & 63.8 & 66 & 150 & 75 & 32 & 63 \\
\hline \multirow[t]{3}{*}{ Low risk } & (4) 2 yearly FS & 162 & 55 & 62.8 & 59 & 190 & 61 & 4 & 39 \\
\hline & (5) 5 yearly FS & 172 & 56 & 63.9 & 57 & 201 & 59 & 4 & 35 \\
\hline & (6) 5 yearly colonoscopy & 134 & 59 & 63.5 & 59 & 165 & 56 & 8 & 29 \\
\hline
\end{tabular}

${ }^{1}$ Including one polyp cancer.

${ }^{2}$ Based on polyps with this information recorded.

FS, flexible sigmoidoscopy; FOB, faecal occult blood. 


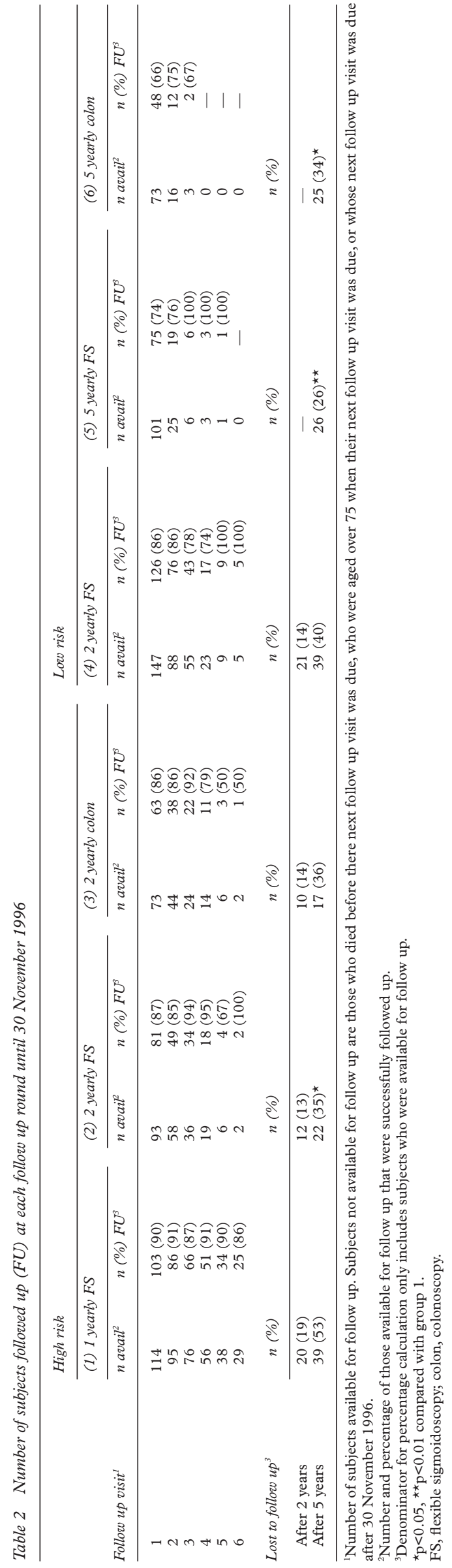

of colorectal cancer occurring in the screening trial with names of those randomised in this trial and ensured notification of colorectal cancers occurring in patients no longer under surveillance or other follow up.

\section{Results}

PATIENT DEMOGRAPHICS AND ADENOMA

CHARACTERISTICS (TABLE 1)

A total of 776 patients were randomised: 307 to the high risk and 469 to the low risk group. Comparison of patient demographics is given in table 1 . There were no significant differences in age or sex between those receiving flexible sigmoidoscopy and colonoscopy as follow up. Numbers recruited because of "family history" were too small to assess.

Recruitment to this study was lower than expected largely due to the fact that the Nottingham Screening Study yielded fewer adenomas than was initially expected.

COMPLIANCE (TABLE 2)

Follow up of patients for the two groups is shown in table 2 . Of the 601 patients available for a follow up visit, 496 (83\%) had at least one follow up. The number available for follow up is those patients randomised to that group who were still alive at the time of that follow up round and aged less than 75 years. The total number of person years of follow up in the study was 5148 years divided between the groups, as shown in table 3 .

ADENOMA RECURRENCE (TABLE 3)

By the end of the study 81 patients had recurrent adenomatous polyps detected, 30 of whom had one that was $>1 \mathrm{~cm}$ in size. The majority of these patients were in high risk group 1 (yearly flexible sigmoidoscopy) (table 3 ). The adenoma recurrence rate was significantly higher in high risk than in low risk patients (relative rate $1.82 ; 95 \%$ confidence interval 1.2-2.9). In two polyps recovered during follow up, carcinoma was discovered within the polyp. Histological examination of these lesions suggested that they had been completely excised at polypectomy and no further procedure was performed. Both patients remain disease free at four and six years following polypectomy.

Although the total number of adenomas identified by flexible sigmoidoscopy was greater than those identified by colonoscopy, the numbers in each group were small and the difference was not statistically significant.

CANCER INCIDENCE (TABLES 4, 5)

During the study, four colorectal cancers were detected, two in high risk group 1 and two in low risk group 5 (table 4). The first cancer was detected in a 76 year old man who presented nine years after entry into the study. He had attended yearly for follow up by flexible sigmoidoscopy. Between examinations he presented with a mass in the right iliac fossa which subsequent barium enema demonstrated to be a caecal carcinoma. Histological examination subsequent to a right hemicolectomy revealed it to be Dukes' stage B. The second tumour was 
Table 3 Polyp recurrence rates by randomisation group

\begin{tabular}{|c|c|c|c|c|c|}
\hline Group & $n$ & $\begin{array}{l}\text { No patients } \\
\text { with polyps }\end{array}$ & $\begin{array}{l}\text { Person years of } \\
\text { follow up in } \\
\text { surveillance study }\end{array}$ & $\begin{array}{l}\text { Total No } \\
\text { person years } \\
\text { of follow up }\end{array}$ & $\begin{array}{l}\text { Polyp recurrence } \\
\text { rate* }(95 \% \mathrm{CI})\end{array}$ \\
\hline \multicolumn{6}{|l|}{ High risk } \\
\hline (1) 1 yearly FS & 115 & 23 & 443 & 816 & $52(35,78)$ \\
\hline (2) 2 yearly FS & 104 & 16 & 340 & 675 & $47(29,77)$ \\
\hline (3) 2 yearly colon & 86 & 10 & 271 & 587 & $37(20,69)$ \\
\hline Total & 305 & 49 & 1054 & 2078 & $47(35,62)$ \\
\hline \multicolumn{6}{|l|}{ Low risk } \\
\hline (4) 2 yearly FS & 162 & 14 & 584 & 1102 & $24(14,41)$ \\
\hline (5) 5 yearly FS & 172 & 13 & 409 & 1167 & $32(19,55)$ \\
\hline (6) 5 yearly colon & 134 & 5 & 261 & 801 & $19(8,46)$ \\
\hline Total & 468 & 32 & 1254 & 3070 & $26(18,36)$ \\
\hline
\end{tabular}

${ }^{\star}$ Per 1000 person years of follow up in surveillance study.

FS, flexible sigmoidoscopy. entry to the study and intubation was performed to the splenic flexure with no abnormality seen. Three years later he presented with large bowel obstruction as an emergency. At laparotomy an obstructing tumour was found in the descending colon and a Hartmann's procedure was performed. Histological examination revealed a Dukes' stage B tumour.

Detection of four cancers in 5138.1 person years of follow up gave an annual incidence of colorectal cancer of $0.78 / 1000$ patients. This compares with an expected incidence of $1.77 / 1000$ patients $(p=0.10)$ (table 5). Only one of four cancers was detected directly by endoscopic surveillance.

COST AND COMPLICATIONS

The NHS procedure costs of flexible sigmoidoscopy and colonoscopy were calculated in 1998 for University Hospital as £96 and $£ 138$, respectively. These costs were calculated on the basis of a consultant performing the endoscopy, with two nurses assisting; depreciation and cleaning costs for equipment were included. However, these values do not include secretarial or pathology costs. The total procedure costs for this study were $£ 121008$. Provision of junior doctor training opportunities were not included.

There was one colonoscopic perforation during this trial. This occurred in a 62 year old man with a difficult diverticular segment. Perforation occurred through a large sigmoid diverticulum and this patient underwent an emergency sigmoid resection and made an uneventful recovery.

\section{Discussion}

The main finding of this study was that polyp recurrence is much less frequent than has previously been reported. In more than 2300

Table 4 Details of polyp cancers and invasive cancers detected during the follow up period

\begin{tabular}{|c|c|c|c|c|c|c|}
\hline & \multicolumn{2}{|l|}{ Polyp cancers } & \multicolumn{4}{|c|}{ Invasive cancers } \\
\hline & 1 & 2 & 1 & 2 & $3 t$ & $4 t$ \\
\hline Randomisation group & 6 & 1 & 1 & 1 & 5 & 5 \\
\hline Age at entry (y) & 64 & 63 & 66 & 55 & 55 & 60 \\
\hline Sex & Male & Male & Male & Female & Female & Male \\
\hline Age cancer detected & 70 & 70 & 76 & 58 & 62 & 70 \\
\hline Follow up round & 1 & 2 & $9^{\star}$ & 2 & - & - \\
\hline Size of tumour $(\mathrm{cm})$ & 2.0 & 1.5 & NK & 3.0 & NK & NK \\
\hline Location of tumour & Transverse colon & Sigmoid & Caecum & Splenic flexure & Caecum & Sigmoid \\
\hline Dukes' stage & A & A & B & $\mathrm{C}$ & $\mathrm{C}$ & B \\
\hline Survival status & Alive & Alive & Alive & Alive & Dead & Alive \\
\hline
\end{tabular}

*Cancer detected at unscheduled visit two months after ninth polyp visit.

†Cancer detected by Nottingham faecal occult blood screening study.

NK, not known, tumour size not stated in histopathology report.

Table 5 Number of person years of follow up stratified by sex and age group, together with observed and expected numbers of cancers

\begin{tabular}{|c|c|c|c|c|c|c|c|}
\hline \multirow[b]{2}{*}{$\begin{array}{l}\text { Time since } \\
\text { baseline }(y)\end{array}$} & \multicolumn{2}{|l|}{ Males } & \multicolumn{2}{|l|}{ Females } & \multicolumn{3}{|l|}{ Total } \\
\hline & $\begin{array}{l}\text { Person years } \\
\text { of follow up }\end{array}$ & $\begin{array}{l}\text { Expected No } \\
\text { cancers }\end{array}$ & $\begin{array}{l}\text { Person years } \\
\text { of follow up }\end{array}$ & $\begin{array}{l}\text { Expected No } \\
\text { cancers }\end{array}$ & $\begin{array}{l}\text { Person years } \\
\text { of follow up }\end{array}$ & $\begin{array}{l}\text { Expected No } \\
\text { cancers }\end{array}$ & $\begin{array}{l}\text { Observed No } \\
\text { cancers }\end{array}$ \\
\hline $0-2$ & 854.4 & 1.428 & 559.3 & 0.681 & 1413.7 & 2.109 & 1 \\
\hline$>2-<5$ & 1056.5 & 1.998 & 707.2 & 0.965 & 1763.7 & 2.963 & \\
\hline $5+$ & 1160.3 & 2.689 & 800.3 & 1.364 & 1960.6 & 4.053 & 3 \\
\hline Total & 3071.2 & 6.115 & 2066.8 & 3.010 & 5138.1 & 9.12 & $4 \dagger$ \\
\hline
\end{tabular}

^From cancers in South East England, 1993, using rates stratified by sex and five year age bands.

†Observed $v$ expected (two sided test), $\mathrm{p}=0.10$. 
patient years of surveillance, only 81 recurrent polyps were detected. The majority of these recurrent polyps occurred in patients perceived to be at "high risk" of developing further adenomas. Only 30 of these adenomas were of a significant size (that is, $>1 \mathrm{~cm}$ ). The relatively low incidence of recurrent adenomas in this study may reflect the entry criteria, in that all patients had a clean colon on colonoscopy and then a further clean colon on flexible sigmoidoscopy six months later, prior to randomisation. It could therefore be argued that even the "high risk" group were only at moderate risk of recurrent polyps. Nevertheless, many units in the UK use this pattern of surveillance-an initial examination followed by a check procedure at approximately one year after polypectomy.

The low incidence of recurrent polyps found in this study is similar to that reported by the Polyp Prevention Study Group. ${ }^{9}$

The fact that only one of four cancers occurring during the surveillance period was detected by surveillance in this study was in part due to the fact that two of these tumours arose beyond the reach of the flexible sigmoidoscope. This leads us to question the use of this instrument for adenoma surveillance.

It is unlikely that cancers have been missed in this study as data were collected from multiple sources. Furthermore, $80 \%$ of the patients in this study were participating in the Nottingham faecal occult blood screening study which mandates that their records are flagged centrally and information fed back to the screening centre. A complete colonic examination in those undergoing flexible sigmoidoscopy may be of benefit in determining whether any more proximal lesions have been missed in this group but this was not part of the original protocol. As most of these patients are part of the Nottingham screening study database and median follow up in this cohort is now 10 years, it seems unlikely that a large number of cancers have occurred in polyps missed on flexible sigmoidoscopy. However, further follow up information on this cohort will become available to confirm this over the next five years. The low incidence of cancers detected would also suggest that the progression rate of flat adenomas is small in this cohort.

The low incidence of recurrent polyps observed in this study is in contrast with the National Polyp Study ${ }^{3}$ in which adenoma surveillance was reported to reduce the incidence of colorectal cancer by $76 \%$ compared with that expected in the general population. However, the Funen adenoma follow up study ${ }^{5}$ reported a reduction in the number of cancers observed compared with the number expected in a population with large adenomas but no reduction in comparison with general population rates. In a study from St Mark's Hospital, removal of rectal adenomas decreased the incidence of rectal cancer in men but not women and the reduction in incidence of rectal cancer failed to reach statistical significance for the group overall. ${ }^{4}$ Other case control studies have shown a significant reduction in the risk of rectal cancer for patients whose rectal polyps have been removed. ${ }^{6}$

More polyps were detected in those patients in the high risk groups. This is expected as large polyp size, more than two adenomas, and villous histology were requirements for entry into the high risk groups and these features have been reported as independent risk factors for the detection of adenomas at follow up. ${ }^{3}$ However, only $16 \%$ of those attending for follow up endoscopy had further adenomas detected. This is lower than reported in previous studies where $37-60 \%$ of patients had adenomas detected at follow up of between three and four years. ${ }^{3}{ }^{10-13}$ Rex and colleagues ${ }^{14}$ reported that the overall miss rate at colonoscopy for adenomas was $24 \%$, although the majority were small polyps and less than $6 \%$ of adenomas $\geqslant 1 \mathrm{~cm}$ in size were missed. It may be that some polyps were missed on follow up endoscopy in all groups in our study but any missed do not seem to have developed into cancers as these would almost certainly have been picked up in the database for the Nottingham screening study. If some were missed it is likely that they were small and unlikely to undergo malignant change in the future.

Overall compliance with follow up was reasonable at $83 \%$. Although attendance for follow up might appear to be lower in those groups with the longest follow up interval when those attending for follow up are expressed as a percentage of the number actually eligible for follow up, but there was no difference between groups. If a patient did not attend for follow up a postal reminder was sent and if the patient did not attend on a second occasion a letter was sent to their general practitioner to say no further appointment would be sent unless specifically requested. While follow up was similar to the $80 \%$ who returned for one or more colonoscopies in the National Polyp Study, these trials represent pursuit of non-attenders which may not be possible outside a research study. Less than perfect follow up must be accepted in the real world where asymptomatic patients are reluctant to have unpleasant procedures performed. Nevertheless, using the NHS central record flagging we have been able to show that this relatively poor compliance with follow up does not seem to have resulted in any cancers been missed.

In this study detection of adenomas and cancer was very expensive. The cost of detecting one adenoma was at least $£ 1500$ and the cost of detecting significant adenomas $>1 \mathrm{~cm}$ in size was over $£ 4000$. The only cancer detected directly by endoscopic follow up was found at a cost of over $£ 120$ 000. This compares with the cost per cancer detected by faecal occult blood testing a general population of about $£ 2000$.

In conclusion, follow up endoscopy for colonic adenomas can be reduced safely to five yearly intervals for the vast majority of patients (excluding patients with hereditary nonpolyposis colorectal cancer and familial adenomatous polyposis). Five yearly examinations 
appear to be associated with similar compliance to two yearly examinations. Partial examination of the colon with repeated flexible sigmoidoscopy cannot be recommended. To make a follow up programme cost effective in both financial and manpower terms, a high risk group needs to be identified and only these patients offered surveillance.

1 Jackman RJ, Mayo CW. The adenoma-carcinoma sequence in cancer of the colon. Surg Gynaecol Obstet 1951;93:327-30. Morson BC. The polyp-cancer se

3 Winawer SJ, Zauber AG, Ho MN, et al. Prevention of colorectal cancer by colonoscopic polypectomy. N Engl f Med 1993;328:1977-81.

4 Atkin WS, Morson BC, Cuzic J. Long-term risk of colorectal cancer after excision of rectosigmoid adenomas. $N$ Engl tal cancer after excision
J Med 1992;326:658-62.

5 Jorgenson OD, Kronborg O, Fenger C. A randomised surveillance study of patients with pedunculated and small sessile tubular and tubulovillous adenomas. The Funen adenoma follow-up study. Scand f Gastroenterol 1995;30: 686-92.
6 Selby JV, Friedman GD, Quesenberry CPJ, et al . A case control study of screening sigmoidoscopy and mortality from colorectal cancer. N Engl F Med 1992;326:653-7.

7 Newcomb PA, Norfleet RG, Storer BE, et al. Screening sigmoidoscopy and colorectal cancer mortality. $\mathcal{F}$ Natl Cancer Inst 1992;84:1572-5.

8 Muller AD, Sonnenberg A. Prevention of colorectal cancer by flexible sigmoidoscopy and polypectomy. Arch Intern Med 1995;155:1741-8.

9 Van Stolk RU, Beck GJ, Baron JA, et al Adenoma characteristics at first colonoscopy as predictors of adenoma recurrence and characteristics at follow up. Gastroenterology 1998;115:13-18

10 Macrae FA, Williams CB. A prospective colonoscopic follow up study of 500 adenoma patients with multivariate analysis to predict risk of subsequent colorectal adenomas. Gastroenterology 1982;82:A1122.

11 Waye JD, Braundfeld SF. Surveillance intervals after colonoscopic polypectomy. Endoscopy 1982;14:79-81.

12 Fowler DL, Hedberg SE. Follow-up colonoscopy after polypectomy. Gastrointest Endosc 1980;26:A67.

13 Neugut AI, Jacobsen JS, Ahsan H, et al. Incidence and recurrence rates of colorectal adenomas: a prospective study. Gastroenterology 1995;108:371-9.

14 Rex DK, Cutler CS, Lemmel GT, et al. Colonoscopic miss rates of adenomas determined by back to back colonoscopies. Gastroenterology 1997;112:24-8. 